Pacific Journal of Mathematics

INFIMUM AND DOMINATION PRINCIPLES IN VECTOR 


\title{
INFIMUM AND DOMINATION PRINCIPLES IN VECTOR LATTICES
}

\author{
Peter A. Fowler
}

The main purpose of this paper is to demonstrate (a) that the potential theoretic notions of infimum principle and domination principle are meaningful in a setting of a vector lattice with a monotone map to the dual space, and (b) in this general setting these two principles are equivalent under very weak hypotheses.

Theorem 1. If $T: L \rightarrow L^{\prime}$ is a strictly monotone map, $L$ a vector lattice, then the infimum principle implies the domination principle.

Theorem 2. If $T: B \rightarrow B^{\prime}$ is a monotone, coercive hemicontinuous map, $B$ a reflexive Banach space and vector lattice with closed positive cone, then the domination principle implies the infimum principle.

1. Introduction. The results herein improve theorems proved earlier by the author [7], and are motivated by work of Calvert [4] and Kenmochi and Mizuta [11, 12]. The paper [4] deals with the Sobolev space $W^{1, m}$ and a monotone operator satisfying certain further conditions. The papers $[11,12]$ deal with functional spaces whose intersection with either $\mathscr{C}$ (continuous compact support functions) or $L^{2}$ is a dense subspace and with a monotone operator which is the gradient of a certain convex function.

The present paper shows that the relationship between the infimum and domination principles is independent of the specialized properties of the above mentioned spaces. This relationship depends more on the lattice structure in a linear space in one case and on the lattice structure in a reflexive Banach space in the other case. Results on monotone operators of Browder [2, Theorem 1] and Hartman and Stampacchia [10, Theorem 1.1] are employed in the Banach space case.

2. Difinitions, Let $L$ be a vector lattice with partial order $\ll$, and $L^{+}=\{x \in L \mid 0 \ll x\}$. The symbol $x \wedge y$ denotes the infimum of $x$ and $y$. Let $L^{\prime}$ be a subspace (possibly improper) of the algebraic dual of $L$. The usual bi-linear form on $L \times L^{\prime}$ is denoted $\langle\cdot, \cdot\rangle$, and $L^{\prime+}=\left\{f \in L^{\prime} \mid\langle x, f\rangle \geqq 0\right.$ for all $\left.x \in L^{+}\right\}$.

Definition 1. A map $T: L \rightarrow L^{\prime}$ is monotone if for all $x, y \in L$, $\langle x-y, T x-T y\rangle \geqq 0 ; T$ is strictly monotone if $T$ is monotone and $\langle x-y, T x-T y\rangle=0$ implies $x=y$. 
In many treatments of kernel-free potential theory in Hilbert or Banach functional spaces $L$, pure potentials are associated with those elements $u \in L$ which satisfy $T u \in L^{\prime+}$. See, for example, Beurling and Deny [1], Fowler [8, 9], Kenmochi and Mizuta [11, 12]. We are thus led naturally to the following definition.

DEFINITION 2. The triple $\left(L, T, L^{\prime}\right)$ satisfies the infimum principle if for each pair $x, y \in L$ such that there exists $z^{\prime} \in L^{\prime}$ with $T x-$ $z^{\prime} \in L^{\prime+}$ and $T y-z^{\prime} \in L^{\prime+}$, it follows that $T(x \wedge y)-z^{\prime} \in L^{\prime+}$.

Suppose $L=\mathscr{X}(X, \xi)$ is a functional space with $L \cap \mathscr{C}$ dense in $L$ and $\mathscr{C}$, as per Example $1, \S 4$. If we insist that $z^{\prime}=T(z)$ with $z \in L$ a potential, then the above infimum principle is that embodied in Theorem 3.2 of Kenmochi and Mizuta [11].

Recall that the cone $L^{\prime}$ induces a partial order $\prec$ on $L^{\prime}$. By adding certain hypotheses it can be assured that $L^{\prime}$ is a vector lattice under this order. See, for example, Day [5, pp. 98-99] or Namioka [13, Theorem 6.7, Corollary 7.3, Theorem 8.7]. If $L^{\prime}$ is a vector lattice, then the above infimum principle is equivalent to the condition:

$$
(T x \wedge T y) \prec T(x \wedge y) \text { for all } x, y \in L \text {. }
$$

(The symbol $\wedge$ is used for infimum in both $L$ and $L^{\prime}$.) To see this equivalence, merely put $z^{\prime}=T x \wedge T y$. The $L^{p}$ spaces, $1 \leqq p$ are examples of this phenomenon.

Definition 3. The triple $\left(L, T, L^{\prime}\right)$ satisfies the domination principle if for each pair $x, y \in L$ such that there exists $z^{\prime} \in L^{\prime}$ with $T x-z^{\prime} \in L^{\prime+}$ and $T y-z^{\prime} \in L^{\prime+}$ and $\left\langle(x-y)^{+}, T x-z^{\prime}\right\rangle=0$ it follows that $x \ll y$.

This is essentially the domination principle of [11, Theorem 3.3] and $[4, p .480]$ stated in an arbitrary vector lattice.

In the next two definitions we assume that $L$ is a Banach space with norm $\|\cdot\|$, and $L^{\prime}$ is the continuous dual.

DeFinition 4. A map $T: L \rightarrow L^{\prime}$ is hemi-continuous if it is continuous from each line segment in $L$ to the weak* topology in $L^{\prime}$.

Definition 5. A map $T: L \rightarrow L^{\prime}$ is coercive if for all $w \in L$, $\langle v-w, T v\rangle /\|v\| \rightarrow+\infty$ as $\|v\| \rightarrow+\infty$.

\section{Theorems.}

THEOREM 1. Let $L$ be a vector lattice. If $T: L \rightarrow L^{\prime}$ is strictly 
monotone and the triple $\left(L, T, L^{\prime}\right)$ satisfies the infimum principle, then it satisfies the domination principle.

Proof. Let $x, y \in L, z^{\prime} \in L^{\prime}$ with $T x-z^{\prime}, T y-z^{\prime} \in L^{\prime+}$ and

$$
\left\langle(x-y)^{+}, T x-z^{\prime}\right\rangle=0 \text {. }
$$

By the infimum principle, $T(x \wedge y)-z^{\prime} \in L^{\prime+}$ so

$$
\left\langle(x-y)^{+}, z^{\prime}-T(x \wedge y)\right\rangle \leqq 0 .
$$

Adding (1) and (2) yields

$$
\left\langle(x-y)^{+}, T x-T(x \wedge y)\right\rangle \leqq 0 .
$$

But $(x-y)^{+}=x-x \wedge y$, so (3) becomes

$$
\langle x-x \wedge y, T x-T(x \wedge y)\rangle \leqq 0 .
$$

Since $T$ is strictly monotone, $x=x \wedge y$, i.e., $x \ll y$.

REMARK. The proof of Theorem 1 is essentially that of [4, Proposition 1.4]. However, it is not required that any notion of infimum exist in the dual space.

We now replace $L$ by a reflexive Banach space $B$ and let $B^{\prime}$ denote the continuous dual. Again, $\ll$ denotes a lattice order on $B$, and $B^{+}, B^{\prime+}$ are as above. We do not assume that the norm of $B$ is a lattice norm [13, p. 41] nor a monotone norm [13, p. 18]. However, for our main result we require that the positive cone $B^{+}$be closed in $B$. As shown in [13, Cor 4.2], this requirement is equivalent to the condition that $x \in B^{+}$if and only if $\langle x, f\rangle \geqq 0$ for all $f \in B^{\prime+}$.

For the purposes of Theorem 2 below, we wish to extend [2, Theorem 1] to a closed convex set $E$ not containing the origin. This will assure the existence of a solution $x_{0} \in E$ to the variational inequality

$$
\left\langle x_{0}-x, T x_{0}\right\rangle \leqq 0 \text { for all } x \in E .
$$

The following lemma permits this simple extension. It is essentially the result given for separable Banach spaces in [6, p. 274].

Lemma. Let $w \in B$ be fixed and $E=K+w$ where $K$ is a closed convex set in $B$ with $0 \in K$. Let $T: B \rightarrow B^{\prime}$ be monotone, hemi-continuous and coercive as defined in $\S 2$. Then there exists $x_{0} \in E$ such that

$$
\left\langle x_{0}-x, T x_{0}\right\rangle \leqq 0 \text { for all } x \in E
$$


Proof. Define $A: B \rightarrow B^{\prime}$ be $A(u)=T(u+w)$. Clearly $A$ is monotone and hemi-continuous. If $\|v\| \geqq\|w\|$ we have for $u=v-w$,

$$
\begin{aligned}
& \frac{\langle v-w, T v\rangle}{2\|v\|} \leqq \frac{\langle v-w, T v\rangle}{\|v\|+\|w\|} \\
& \leqq \frac{\langle v-w, T v\rangle}{\|v-w\|}=\frac{\langle u, T(u+w)\rangle}{\|u\|} \\
& \quad=\frac{\langle u, A u\rangle}{\|u\|} .
\end{aligned}
$$

Thus the coercive condition on $T$ entails $\langle u, A u\rangle /\|u\| \rightarrow+\infty$ as $\|u\| \rightarrow+\infty$. Since $0 \in K$ it follows from [2, Theorem 1] that there exists $u_{0} \in K$ such that

$$
\left\langle u_{0}-y, A u_{0}\right\rangle \leqq 0 \text { for all } y \in K .
$$

Put $x_{0}=u_{0}+w, x=y+w$. Then $x, x_{0} \in E, T x_{0}=A u_{0}$ and the result follows.

Theorem 2. Let the triple $\left(B, T, B^{\prime}\right)$ satisfy the domination principle with $B$ a reflexive Banach space and vector lattice, $B^{+}$ closed, and $T$ a monotone, hemi-continuous, coercive map. Then $\left(B, T, B^{\prime}\right)$ satisfies the infimum principle.

Proof. Let $x, y \in B, z^{\prime} \in B^{\prime}$ with $T x-z^{\prime}, T y-z^{\prime} \in B^{\prime+}$. Define

$$
E=x \wedge y+B^{+}=\{u \in B \mid x \wedge y \ll u\} .
$$

It is immediate that $E$ is convex and closed. Define $S: B \rightarrow B^{\prime}$ by $S u=T u-z^{\prime}$. Clearly $S$ is monotone, hemi-continuous and coercive since $T$ has these properties. By the lemma applied to $S$, there exists $x_{0} \in E$ such that

$$
\left\langle u-x_{0}, S x_{0}\right\rangle \geqq 0 \text { for all } u \in E .
$$

But for any $v \in B^{+}, v=\left(v+x_{0}\right)-x_{0}$ and $v+x_{0} \in E$, so (4) entails $S x_{0} \in B^{+}$, i.e.,

$$
T x_{0}-z^{\prime} \in B^{\prime+} \text {. }
$$

It remains to show $x_{0}=x \wedge y$. Now $x_{0} \wedge x \ll x_{0}$, so $x_{0}-\left(x_{0} \wedge x\right) \in B^{+}$, and (5) entails

$$
\left\langle x_{0}-\left(x_{0} \wedge x\right), T x_{0}-z^{\prime}\right\rangle \geqq 0 .
$$

But $x_{0} \in E, x \in E$ and the definition of $E$ imply $x \wedge y \ll x_{0}$ and $x \wedge y \ll x$, so $x \wedge y \ll x_{0} \wedge x$, i.e., $x_{0} \wedge x \in E$. Thus (4) entails

$$
\left\langle x_{0}-x_{0} \wedge x, T x_{0}-z^{\prime}\right\rangle \leqq 0 \text {. }
$$


By (6) and (7) we see $\left\langle x_{0}-x_{0} \wedge x, T x_{0}-z^{\prime}\right\rangle=0$, i.e., $\left\langle\left(x_{0}-x\right)^{+}, T x_{0}-\right.$ $\left.z^{\prime}\right\rangle=0$. Thus, (5) and the assumption that $T x-z^{\prime} \in B^{+}$and the domination principle yield $x_{0} \ll x$. Analogously, $x_{0} \ll y$, so $x_{0} \ll x \wedge y$. By definition of $x_{0} \in E$ we have $x \wedge y \ll x_{0}$. Since a lattice order is necessarily anti-symmetric, it follows that $x_{0}=x \wedge y$ and thus $T(x \wedge y)-z^{\prime} \in B^{\prime+}$.

\section{Examples.}

ExAmple 1. Lex $X$ be a locally convex Hausdorff space with countable base and $\xi$ a positive Radon measure on $X$. Let $\mathscr{X}=$ $\mathscr{Z}(x, \xi)$ be a reflexive Banach functional space as in [11, p. 744]. For $1<m<\infty$ let $\Phi$ be a strictly convex real valued function on $\not \mathcal{E}$ satisfying

$$
\begin{aligned}
& \Phi(0)=0 \\
& \Phi(u) \geqq k\|u\|^{m} \quad \text { for all } u \in \mathscr{H},
\end{aligned}
$$

$k$ a positive constant. Also, let $\Phi$ be bounded on bounded sets and the gradient $\nabla \Phi$ exist at each $u \in \mathscr{X}$ :

$$
\langle v, \nabla \Phi(u)\rangle=\lim _{t \rightarrow 0+} \frac{\Phi(u+t v)-\Phi(u)}{t} .
$$

Then $\nabla \Phi: \mathscr{X} \rightarrow \mathscr{Q}^{\prime}$ is a strictly monotone, hemi-continuous and coercive operator. See $[11,12]$. Necessary conditions for the infimum and domination principles to hold are therein discussed at length.

ExAmple 2. Let $\Omega \subset R^{n}$ be open. For $1<p<\infty$ the space $W_{0}^{1, p}(\Omega)$ is the closure of $\mathscr{D}(\Omega)$, the test space for distributions, in the Sobolev space $W^{1, p}(\Omega)$ in norm

$$
\|u\|=\left(\sum_{|j| \leq 1}\left\|D^{j} u\right\|_{L^{p}}^{p}\right)^{1 / p} .
$$

It was shown in $\left[9\right.$, p. 322] that the spaces $W_{0}^{1, p}$ and $W^{1, p}$ are uniformly convex, smooth functional spaces and vector lattices and thus satisfy the requirements of Example 1 above.

EXAMPLE 3. For $p>1,0<\alpha<1$ and $2 n /(n+2 \alpha)<p$, the fractional Sobolev space $L_{\alpha}^{p}\left(R^{n}\right)$ is the set of $f \in L^{p}\left(R^{n}\right)$ such that $\mathscr{D}_{\alpha} f \in L^{p}\left(R^{n}\right)$, where

$$
\mathscr{D}_{\alpha} f(x)=\int_{R^{n}}|f(x)-f(y)|^{2} \frac{d y}{|x-y|^{n+2 \alpha}} .
$$

The norm is $\|f\|_{\alpha}=\left(\|f\|_{L^{p}}^{p}+\left\|\mathscr{D}_{\alpha}\right\|_{L^{p}}^{p}\right)^{1 / p}$. In [9, p. 324] it is shown 
that $L_{\alpha}^{p}$ is a smooth, uniformly convex Banach-Dirichlet space [9, p. 311] and thus a vector lattice satisfying the requirements of Example 1.

EXAMPLE 4. Let $B$ be a reflexive Banach space with continuous dual $B^{\prime}$. Let $T: B \rightarrow B^{\prime}$ be a duality map, i.e.,

$$
\langle u, T(u)\rangle=\|u\|\|T u\|=\|u\| \varphi(\|u\|) \text { for all } u \in B
$$

where $\varphi: R^{1} \rightarrow R^{1}$ is a continuous, strictly increasing function with $\varphi(0)=0$ and $\lim _{r \rightarrow+\infty} \varphi(r)=+\infty$. Then $T$ is coercive because for fixed $w \in B$,

$$
\begin{aligned}
\langle v-w, T v\rangle /\|v\| & \geqq\|T v\|-\frac{\|w\|\|T v\|}{\|v\|} \\
& =\varphi(\|v\|)(1-\|w\| /\|v\|) \rightarrow+\infty
\end{aligned}
$$

as $\|v\| \rightarrow+\infty$. It is shown in [3, p. 368] that $T$ is monotone, and if $B$ is strictly convex then $T$ is strictly monotone. Further, if $B$ is smooth, then corresponding to each $\varphi$ in the definition of duality map, there is a unique, hemi-continuous duality map $T .^{1}$

\section{REFERENCES}

1. A. Beurling and J. Deny, Dirichlet spaces, Proc. N. A. S., 45 (1959), 208-215.

2. F. Browder, Nonlinear monotone operators and convex sets in Banach spaces, Bull. Amer. Math. Soc., 71 (1965), 780-785.

3. F. Browder, On a theorem of Beurling and Livingston, Canad. J. Math., 17 (1965), 367-372.

4. B. Calvert, Potential theoretic properties for monotone operators, Bull. U. M. I., (4) 5 (1972), 473-489.

5. M. M. Day, Normed linear spaces, Ergebnisse der Mathematik und ihrer Grenzgebeite, Neue Folge, Heft 21, Berlin-Göttingen-Heidelberg, 1962. 2d printing corrected. 6. Deny, Jacques, Quolques mothods de resolution des problems limites non-lineaires, Dunod, Gauthier-Villars, Paris, 1969.

7. P. Fowler, An axiomatic potential theory in uniformly convex Banach spaces of functions, thesis directed by J. Elliott, Rutger, 1968.

8. - Capacity theory in Banach spaces, Pacific. J. Math., 48 (1973), 365-385.

9. - Potential theory in Banach spaces of functions, a condensor theorem, J. Math. Anal. Appl., 33 (1971) 310-327.

10. P. Hartman and G. Stampacchia, On some nonlinear elliptic differential functional equations, Acta Math. Uppsala, 115 (1966), 271-310.

11. N. Kenmochi and Y. Mizuta, Gradient of a convex function on a regular functional space and its potential theoretic properties, to appear, Hiroshima Math. J., 4 (1974).

12. - Potential theoretic properties of the gradient of a convex function on a functional space, to appear, Nagoya Math. J.

1 In the author's opinion, it was incorrectly reported in [3, p. 371] that $T$ corresponding to $\varphi$ is unique and continuous from $B$ to the weak topology of $B^{\prime}$ if $B$ is strictly convex. A note indicating this and that Theorem 4 of [3] is incorrect, together with counterexample and correction, has been submitted elsewhere. 
13. I. Namioka, Partially ordered linear topological spaces, Memiors Amer. Math. Soc., N. 24 (1957).

Received September 23, 1974.

California State University-Hayward 



\title{
PACIFIC JOURNAL OF MATHEMATICS
}

\section{EDITORS}

RichaRd ARENS (Managing Editor)

University of California

Los Angeles, California 90024

\section{R. A. Beaumont}

University of Washington

Seattle, Washington 98105
J. DUGUNDJI

Department of Mathematics University of Southern California Los Angeles, California 90007

D. Gilbarg and J. Milgram

Stanford University

Stanford, California 94305

\section{ASSOCIATE EDITORS}
E. F. BECKENBACH
B. H. NeUmanN
F. WOLF
K. YoshIDA

\section{SUPPORTING INSTITUTIONS}

\author{
UNIVERSITY OF BRITISH COLUMBIA \\ CALIFORNIA INSTITUTE OF TECHNOLOGY \\ UNIVERSITY OF CALIFORNIA \\ MONTANA STATE UNIVERSITY \\ UNIVERSITY OF NEVADA \\ NEW MEXICO STATE UNIVERSITY \\ OREGON STATE UNIVERSITY \\ UNIVERSITY OF OREGON \\ OSAKA UNIVERSITY
}

\author{
UNIVERSITY OF SOUTHERN CALIFORNIA \\ STANFORD UNIVERSITY \\ UNIVERSITY OF TOKYO \\ UNIVERSITY OF UTAH \\ WASHINGTON STATE UNIVERSITY \\ UNIVERSITY OF WASHINGTON \\ AMERICAN MATHEMATICAL SOCIETY
}

The Supporting Institutions listed above contribute to the cost of publication of this Journal, but they are not owners or publishers and have no responsibility for its content or policies.

Mathematical papers intended for publication in the Pacific Journal of Mathematics should be in typed form or offset-reproduced, (not dittoed), double spaced with large margins. Underline Greek letters in red, German in green, and script in blue. The first paragraph or two must be capable of being used separately as a synopsis of the entire paper. Items of the bibliography should not be cited there unless absolutely necessary, in which case they must be identified by author and Journal, rather than by item number. Manuscripts, in triplicate, may be sent to any one of the editors. Please classify according to the scheme of Math. Reviews, Index to Vol. 39. All other communications should be addressed to the managing editor, or Elaine Barth, University of California, Los Angeles, California, 90024.

The Pacific Journal of Mathematics expects the author's institution to pay page charges, and reserves the right to delay publication for nonpayment of charges in case of financial emergency.

100 reprints are provided free for each article, only if page charges have been substantially paid. Additional copies may be obtained at cost in multiples of 50 .

The Pacific Journal of Mathematics is issued monthly as of January 1966. Regular subscription rate: $\$ 72.00$ a year (6 Vols., 12 issues). Special rate: $\$ 36.00$ a year to individual members of supporting institutions.

Subscriptions, orders for back numbers, and changes of address should be sent to Pacific Journal of Mathematics, 103 Highland Boulevard, Berkeley, California, 94708.

PUBLISHED BY PACIFIC JOURNAL OF MATHEMATICS, A NON-PROFIT CORPORATION

Printed at Kokusai Bunken Insatsusha (International Academic Printing Co., Ltd.), 8-8, 3-chome, Takadanobaba, Shinjuku-ku, Tokyo 160, Japan.

Copyright (C) 1975 by Pacific Journal of Mathematics Manufactured and first issued in Japan 


\section{Pacific Journal of Mathematics}

\section{Vol. 59, No. $2 \quad$ June, 1975}

Aharon Atzmon, A moment problem for positive measures on the unit disc ........

Peter W. Bates and Grant Bernard Gustafson, Green's function inequalities for

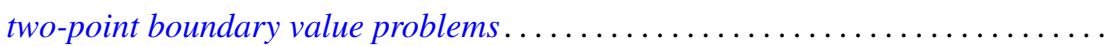

Howard Edwin Bell, Infinite subrings of infinite rings and near-rings ...........

Grahame Bennett, Victor Wayne Goodman and Charles Michael Newman, Norms of

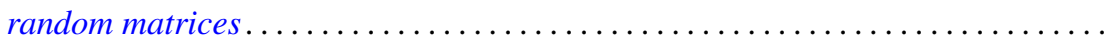

Beverly L. Brechner, Almost periodic homeomorphisms of $E^{2}$ are periodic.........

Beverly L. Brechner and R. Daniel Mauldin, Homeomorphisms of the plane ........

Jia-Arng Chao, Lusin area functions on local fields ......................

Frank Rimi DeMeyer, The Brauer group of polynomial rings ...............

M. V. Deshpande, Collectively compact sets and the ergodic theory of

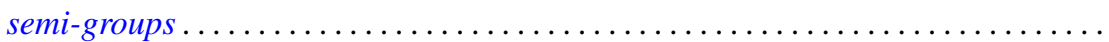

Raymond Frank Dickman and Jack Ray Porter, $\theta$-closed subsets of Hausdorff

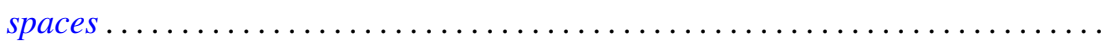

Charles P. Downey, Classification of singular integrals over a local field .......... 407

Daniel Reuven Farkas, Miscellany on Bieberbach group algebras . . . . . . . . . . . .

Peter A. Fowler, Infimum and domination principles in vector lattices . . . . . . . . . .

Barry J. Gardner, Some aspects of T-nilpotence. II: Lifting properties over

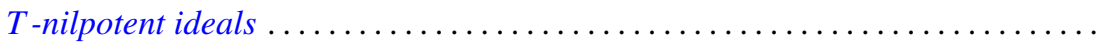

Gary Fred Gruenhage and Phillip Lee Zenor, Metrization of spaces with countable

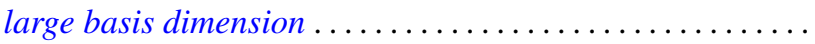

J. L. Hickman, Reducing series of ordinals...

Hugh M. Hilden, Generators for two groups related to the braid group ...

Tom (Roy Thomas Jr.) Jacob, Some matrix transformations on analytic sequence

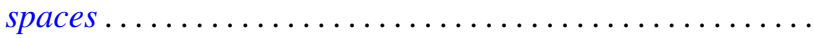

Elyahu Katz, Free products in the category of $k_{w}$-groups . .....

Tsang Hai Kuo, On conjugate Banach spaces with the Radon-Nikodým property...

Norman Eugene Liden, $K$-spaces, their antispaces and related mappings ...

Clinton M. Petty, Radon partitions in real linear spaces ........

Alan Saleski, A conditional entropy for the space of pseudo-Menger maps ....

Michael Singer, Elementary solutions of differential equations .

Eugene Spiegel and Allan Trojan, On semi-simple group algebras. I. . .

Charles Madison Stanton, Bounded analytic functions on a class of open Riemann

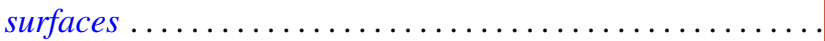

Sherman K. Stein, Transversals of Latin squares and their generalizations ....

Ivan Ernest Stux, Distribution of squarefree integers in non-linear sequences . . .

Lowell G. Sweet, On homogeneous algebras ................

Lowell G. Sweet, On doubly homogeneous algebras .......... .

Florian Vasilescu, The closed range modulus of operators ......

Arthur Anthony Yanushka, A characterization of the symplectic groups $\operatorname{PSp}(2 m, q)$

as rank 3 permutation groups... 